\title{
Integrating animals in the classroom: The attitudes and experiences of Australian school teachers toward animal-assisted interventions for children with Autism Spectrum Disorder.
}

\author{
Bradley P Smith and Ashley A Dale ${ }^{1}$
}

Abstract

The introduction of animals into school classrooms has been posited as a beneficial intervention for individuals with Autism Spectrum Disorder (ASD). Whilst evidence that animal-assisted interventions or activities can positively influence classroom behaviour and learning outcomes is emerging, little is known about the experiences and attitudes of those who implement it. We presented a series of open and closeended questions via an online survey to Australian school teachers working with students on the autistic spectrum. Whether teachers had experienced companion animals in the classroom or not, companion animals were believed to provide a means for improving social skills and engagement within the classroom, as well as decreasing stress, anxiety, and the occurrence of problematic behaviours. Yet, despite an overall positive attitude, and $68 \%$ having had animals or pets in their classroom, only $16 \%$ of respondents had experience with 'formal' animal-assisted interventions. Explanations for why both formal and informal animal-assisted interventions were either not being adopted, or was not currently being considered, included a lack of knowledge, lack of support and resources, reactions of the student in relation to allergies and behaviour, and issues relating to animal welfare. It was also acknowledged that the evidence-base for animal-assisted interventions for students with ASD is currently lacking, and that such interventions were not suitable for all students, or all classroom situations. Moving forward, it is important that the inclusion of companion animals and more formal based animal intervention programs in classrooms be adequately designed and evaluated, because implementing or promoting time consuming and financially costly strategies without the evidence is problematic.

Pet Behaviour Science | 2016, Vol. 1, 13 - 22

Bradley P Smith and Ashley A Dale

1. Central Queensland University

Paper Research

Email:

b.p.smith@cqu.edu.au

Australia

Keywords:

Animals; companion animals; animal-assisted activities; Autism Spectrum Disorder; special education; school; teacher attitudes.

\section{HIGHLIGHTS}

Providing children with the opportunity to interact with animals in classroom settings has many potential benefits, especially for individuals with Autism Spectrum Disorder.

Yet, our understanding of the experiences and attitudes of school teachers towards integrating animals in the classroom is limited. 
This study begins the process of uncovering some of the benefits and barriers relating to the integration of animals in Australian schools.

The inclusion of animals in classrooms, particularly dedicated animal-assisted therapies, needs to be adequately evaluated, as introducing time consuming and financially costly interventions without adequate evidence is problematic.

\section{INTRODUCTION}

The physical, social and emotional benefits that can be achieved through human-animal interactions has led to the rise of animal-assisted interventions as a treatment option for a variety of clinically diagnosed conditions (Nimer and Lundahl 2007). This includes neurodevelopmental disorders such as Autism Spectrum Disorder (ASD) (Grandin et al. 2010; O'Haire 2013). ASD is a chronic disorder that emerges throughout childhood. It is characterised by significant deficits in social interaction and communication, and the presence of restricted and repetitive interests (American Psychiatric Association 2013). These deficits often lead to on going negative consequences for the individual, family (Smyth and Slevin 2010), and the economy (Roth 2013). A sharp rise over the last decade of children diagnosed with ASD (Roth 2013) has signalled a need for effective interventions, particularly those that are economically viable (Lord et al. 2005), and can be conducted in school-based environments (Anderson and Olson 2006; Berry et al. 2013).

One viable treatment option available for teachers, school counsellors and psychologists in educational settings involves the promotion of animal contact (Kaufmann 1997; Chandler 2001). The term 'animalassisted interventions' has been used to describe the formal (animal-assisted therapy) as well as the less formal (animal-assisted activities) treatment options. Animal-assisted therapy involves the deliberate and purposeful inclusion of an animal to help participants meet specific treatment goals that may be best addressed or facilitated with the assistance of the animal. However animal-assisted activities encourages activities with animals to provide opportunities for motivational, educational, recreational, and/or therapeutic benefits without the presence of specified treatment goals or objectives. The latter does not have to be implemented by trained personnel, and session content is spontaneous (Nimer and Lundahl 2007; Fine 2010; O’Haire et al. 2014).

Numerous studies have highlighted the benefits of animal-assisted interventions for school aged children, particularly children on the autistic spectrum (Hergovich et. al. 2002; Kotrschal and Ortbauer 2003; Jalongo et al. 2004; Anderson and Olson 2006; Friesen and Delisle 2007; Daly and Suggs 2010; Grandgeorge et. al. 2012; O'Haire et al. 2013; O'Haire, et al. 2014). The ability of an animal to change the dynamic of the classroom to be more positive and engaging has been recognised and harnessed into the creation of specific animal-assisted programs, such as ones focusing on literacy (Jalongo 2005). Domestic dogs, with which children with ASD can form strong bonds (Carlisle 2015), have been successfully used in classrooms to support student learning through modelling trust and acceptance, and have been linked to an increase in positive attitudes towards other students, learning, and attendance (Anderson and Olson 2006; Friesen and Delisle 2007; Jalongo et al. 2004; Beetz 2013).

Animal-assisted interventions may also serve as a conduit for pro-social behaviours, such as social inclusion, play, communication and bonding opportunities for ASD students (Friesen and Delisle 2007; O'Haire et al. 2013). In one study for example, typically developing peers were ten times more likely to interact with a fellow student who had a disability if they were in the company of a dog (Jalongo et al. 2004). Several evaluations of animal-assisted programs for children with ASD have reported increases in overall social and emotional behaviours such as verbal, gestural and visual communication towards the animal, teachers' and peers, and decreased self-absorption and self-stimulatory play (Kršková et al. 2010; O'Haire et al. 2013; Silva, et al. 2011; Carlisle 2015). Teachers regularly report positive changes in students when animals have been involved in the classroom, such as sustained emotional benefits to animal and human-directed empathy, increased social interactions, reduced aggressive behaviours and a decrease in hyperactivity, all of which are domains where students with ASD require support (Ascione and Weber 1996; Hergovich et. al. 2002; Daly and Suggs 2010). 
Although there is a great deal of anecdotal evidence that animals can lead to beneficial outcomes for certain individuals with ASD, there are few scientifically rigorous studies evaluating the use of assistance animals in classroom settings (see Nimer and Lundahl 2007 and O'Haire 2013 for reviews). The evaluations that exist suggest that the use of animals in classrooms (and elsewhere), although promising, suffer from methodological issues (e.g. single-subject experimental designs), only show small to moderate effects in relation to improving outcomes, and have yet to be shown to promote long term and meaningful change (Nimer and Lundahl 2007; O'Haire 2013; Kasari and Smith 2013). Part of the issue with conducting such evaluations is the breadth of animal-related interventions available, the contexts and disciplines in which the use of animals in classrooms have been implemented, and the teaching strategies used (likely a reflection of inadequate training, support, and intervention manuals available).

In addition to a paucity of scientific evidence, several practical barriers to introducing animals in classrooms have been identified (Hergovich et. al. 2002; Kotrschal and Ortbauer 2003; Prothmann et al. 2009). A study of teachers in the United States highlighted several factors preventing teachers from having classroom pets including policy and legal concerns; a dislike of animals; a lack of adequate space for the animal; and the potential of an increased workload (Rud and Beck 2003). Ladarola et al. (2015) found several challenges in introducing new interventions into schools for children with ASD. These included tension between stakeholders (i.e., between staff and administration, staff and parents, special education and general education teachers), lack of training, and a lack of culture of accepting difference. It is likely, but uncertain whether these perceptions and challenges exist in the Australian school context.

Teachers' play a pivotal role in the implementation and success of classroom interventions. Understanding the association between teacher attitudes, experiences, and their likelihood of integrating animals in classrooms therefore, is paramount to animal-assisted interventions becoming more widely practised. It also increases the opportunity for such interventions to be appropriately evaluated. This study begins the process of uncovering some of the obstacles that may prevent the successful integrating of companion animals and animal-assisted interventions in Australian schools from the perspective of those that implement it.

\section{METHODS}

\section{Participants}

A total of 73 current Australian school teachers working specifically with students diagnosed with Autism Spectrum Disorder participated in the online survey (67 female, 5 male). Just over half were aged between 25 - 34 years (53.0\%), with $15.8 \%$ between 45 and $54,10.5 \%$ between 55 and 64 years, $13.2 \%$ between $35-44$ years, $6.6 \%$ between $18-24$, and $1.3 \%$ between 65 74 years of age. The majority of the sample had positive inclinations towards animals, with $90.4 \%$ identifying as 'an animal person', and animal ownership among the sample $(74.0 \%)$ slightly above the national average (Australian Companion Animal Council, 2010). The total amount of teaching experience varied across the sample, with $65.8 \%$ having between 1 and 10 years experience, $13.7 \%$ between 11 and 20 years, and $17.9 \%$ with 21 or more years experience.

The majority of the teachers worked in State/Government schools (78.1\%), and identified the schools as residing within either an urban $(68.5 \%)$ or rural setting (31.5\%). Participants taught across all year levels, with $32.9 \%$ working in a primary school, $24.7 \%$ in a secondary school, and $9.6 \%$ in a joint primary/secondary (prep to year 12) school. About one third of teachers $(32.9 \%)$ worked specifically within a special education context.

\section{Materials}

The research team designed an online questionnaire based on the literature on animal-assisted interventions in general. The survey included a maximum of 58 question items (41 closed and 14 open-ended questions). The exact number of questions answered was determined by responses to specific items. Questions required responses to a mixture of yes/no questions, list of options, Likert-type scales, and openended questions. The questionnaire covered topics relating to the participant (e.g. gender, age, education, 
training specialisation, current position, number of years teaching); the school where they were employed at the time of the survey (e.g. number of students, location, percentage of students that own pets, the degree to which animals play in the lives of the children); their attitudes towards animals (e.g. current and past animal ownership, whether they identify as an animal person, negative experiences with animals); their experience and knowledge of animal-assisted therapies (e.g. whether they had read any information on animal-assisted therapies and what prompted the search, what animals they believe would be effective in the classroom, training with animal-related therapies, whether the school has active animal programs, the details of such programs including what sessions or activities animals were used for, and reasons for involving animals); potential barriers that exist preventing them from having used or including animals in the classroom; and resources that might be needed in order to develop an animal-related program. Open ended questions included, for example; "What is the first thing that comes to mind when you hear the phrase animal-assisted therapy?"; "In 150 words or less, please provide a brief example of how animalassisted therapy was successful [or not] in achieving your initial goals"; "In 150 words or less, please provide some insight into your likelihood of continuing, or not continuing, to use animal-assisted therapy"; "Please explain or list some of the reasons why you have not had a pet in the classroom"; and "Do you have any other comments relating to animalassisted therapy and children with autism spectrum disorder that you would like to share?". Questionnaire is available from the author by request.

\section{Procedure}

Australian teachers with experience teaching children with Autism Spectrum Disorder were invited to partake in an anonymous survey through various online interest groups that encouraged teachers to communicate and share knowledge and best practices. Members who chose to participate were directed to an online survey and provided further detailed information about the study and a consent form. The survey was available between July and October 2014, and took approximately 20 minutes to complete. The project was approved by the Central Queensland
University Human Research Ethics Committee (H14/05-094).

Analyses

Closed-ended response items were analysed using descriptive statistics. A thematic analytical approach (Braun and Clarke, 2006) was utilized to identify the main themes within the data corpus. Thematic analysis is a rigorous method of discourse analysis useful for analysing patterns (themes) within a data corpus. The first stage of analysis requires data familiarisation, and therefore involved reading over the qualitative responses. In the second stage, the data were searched, asking three major questions: (1) What are the motivators for integrating companion animals into the classroom; (2) What are the perceived benefits of integrating companion animals into the classroom; (3) What are the perceived barriers to the integration of animals into the classroom? Extracts from participants' responses were collated under each of these three questions. These extracts were discussed within the research team to establish agreement that they were coherent with the themes and representative of the patterns across different participants' responses (Green et al. 2007).

\section{RESULTS}

Experience And Knowledge Of Animal-Assisted Classroom Interventions

The majority of teachers had had animals or pets in their classroom $(68 \%)$, with a total of 14 teachers $(18 \%$ of respondents) reported having directly experienced formal animal-assisted therapy in the classroom. Only $5 \%$ of all teachers were currently working in a school that had an active animal-related program. The majority of teachers who had incorporated animals worked in special education schools $(50 \%)$, were situated within a city/metro location $(75 \%)$, and were government based/public (66.6\%). The experience of teachers who had engaged with animal-assisted interventions varied, with years of teaching ranging between 5 to 44 years of age. Teachers were mostly between 55-64 years (66.6\%), followed by those between 25-34 years (33.3\%). For teachers who had not been directly involved with animals in the classroom, 
an overwhelming number $(96.7 \%)$ expressed interest in pursuing it in the future.

When asked to rank a provided list of 10 animals by their perceived effectiveness for classroom based interventions, domestic dogs were ranked as number 1 by $60 / 75$ ( $80 \%$; Mean ranking 1.77$)$, followed by cats as number 2 (38\%; Mean ranking 4.2), and rabbits as number 3 (31\%; Mean ranking 3.97). Animals used in existing animal-therapy programs primarily involved the use of domestic dogs $(n=3)$, but the list of species extended to horses, rabbits, guinea pigs, chickens, and farm animals (with each species/group being identified by one respondent)

A quarter $(26 \%)$ of teachers surveyed had read literature relating to animal-assisted interventions. When prompted for the source of the information, participants mentioned academic journal articles, followed by newspaper articles, set readings as part of a university course, and the internet. When asked what encouraged them to research animal-assisted interventions, few had actively sought out the material, but had heard about it from colleagues, reading about it whilst studying at university, or in a general articles in the newspaper. Only two teachers surveyed had ever received any formal training with animal-assisted therapies, however most $(80.8 \%)$ indicated they would be interested in attending a training session.

\section{Motivators For Integrating Companion Animals Into The} Classroom

When asked why they would consider involving animals or animal-assisted therapies as an intervention for students with ASD, teachers gave a range of motivators. Animals were identified as being able to offer something unique to the therapeutic and/or classroom environment. That is, animals resonated specifically with children with ASD, and could be useful in a wide variety of contexts.

"Have always believed that animals have a way of reaching children that don't always respond well to adults or their peers"

"Animals do not discriminate nor judge others and can be trained to provide specific therapy to individuals. They bring out the best in people and give teachers more insight into students strengths"

"Animals generally provide an avenue to encourage ASD children to actively participate in the world, rather than existing in retreat/ solitude"

A personal interest in the intervention was expressed, as was a willingness to try new 'things' or 'methods' that might benefit their students. Some took this further, indicating that it was their responsibility to find the most effective methods for individual students, but recognising that animal-assisted interventions may be effective for some, but not all.

"I work with many children with ASD. Each child is different and as a teacher, it is my aim and responsibility to discover what works for each child to better their learning experience"

"It depends on the student and their situation but if they like animals it might be a different perspective to helping them"

There were some teachers who were already convinced that animal-assisted interventions are effective, and "been proven to work". The rationale behind such strong views were not explored further. However, in a few cases, teachers had witnessed animal-assisted interventions being used effectively, and wanted to try it out with their own students.

"I have visited a school where they have two golden retrievers as school pets and I was very impressed at the calm that they bought to a classroom and the obvious affection that the students had for them"

\section{Perceived Benefits Of Integrating Companion Animals Into} The Classroom

Teachers who had introduced companion animals into their classrooms were prompted to share their experiences and provide brief examples of success. All reported positive experiences, and described a range of benefits to individual students as well as the classroom as a whole. Perceived benefits of animal-assisted interventions fell into four distinct themes, including: 
Improving social skills.

A variety of the social deficits that affect individuals with ASD were reported to have improved considerably when animals were present.

"ASD students often show a strong bond with their pets and the ability to be open and expressive with these animals"

"The dog taught an autistic child to play fetch. The child previously didn't interact or play with people and was afraid of animals"

"Teaching students turn taking skills and engaging students with animals and treating animals with respect"

\section{Facilitating student engagement.}

It was noted that particular students were more likely to be focused and engaged in learning and participate in the classroom and curriculum based activities when animals were present.

"Kids love animals-yes, it's a generalization but 'generally' they do. The children in my class would talk all day, if I let them, about their pets and their antics. They all bought along pet photos"

"Positive opportunity for teachers to engage children in games and fun and to enhance their participation and willingness to read"

\section{Decreased student stress and anxiety.}

Without a feeling of connectedness to the learning episode, peers or teacher, the classroom often becomes an environment where stress and anxiety, as well as problem behaviours rise and interfere with learning and social interaction.

"Students were drawn to the animal and displayed decreased anxiety and arousal. This calming nature allowed good discussion time and focus for students"

"A student was very anxious and upset as he has not been picked up at school to go home. Minty (Animal Assisted Therapy dog) calmed the student while waiting"
Reducing problem behaviours.

In addition to a decrease in stress and anxiety in students with ASD, a decrease in problem behaviours were also noted.

"I believe animals can transcend minor difficulties with mood and behaviour as they have keen senses and naturally helpful attitudes"

"Therapy dog worked with one of the OTs [occupational therapist] in the school. Was an incentive for students with behavioural concerns. Dog made some children very happy"

\section{Perceived Barriers To The Integration Of Animals Into The Classroom}

Despite the encouraging examples provided by those who had experience with companion animals in the classroom, the teachers in this sample identified multiple barriers that they either have experienced, or expect to experience regarding the successful introduction of animals within their school and or classroom. Some key logistical issues that prevented the use of animals included the employment status of the teacher (i.e., casual or part time teachers reported that it were difficult to instigate any animal related programs), and where animals were perceived not to be of obvious benefit to the subjects or classes being taught (e.g. maths, history and geography teachers felt animals would not provide any additional benefit). Employment status and subject aside, several concerns or perceived barriers were raised that could be grouped according to four major themes:

\section{A lack of knowledge.}

A common barrier identified by teachers was a lack of knowledge about animal-assisted intervention, as well as how to access suitable information. Of particular concern, was the lack of evidence base for which to support the decision to introduce animals (or animalrelated therapies) into the classroom.

"If research showed that AAT [Animal Assisted Therapy] could have a positive benefit for my students with ASD I would be willing to try it" 
"I think it is a developing area and evidence based practices are required before a higher level of implementation occurs"

\section{A lack of support and facilities.}

Teachers felt that they would not have the support of their school if they were to enquire about implementing animal-assisted interventions. This includes resources (space, facilities, and funding) as well as support from administration.

"I think it's a great idea, especially if the program could focus on providing information to principals and getting them 'on board'"

\section{Animal welfare concerns.}

Teachers expressed concern for the well being of the animals when interacting with the children.

"Dog was overwhelmed by students who had not yet been able to have their own needs met and therefore were unresponsive to the animals needs"

In addition, animal-assisted interventions were likely to cause additional work beyond the classroom, particularly the adequate care for the animal outside of school hours.

"Need to have a teacher that is willing to take an animal for training and house the animal. Not very easy with most staff already having animals"

"Issues arose when the dog was sick and required careful management and support for students and staff and when therapy dog had to be retired"

\section{Student behavioural reactions and allergies.}

Another apprehension surrounded the reaction of the students to the animals. Teachers felt that not all students would react well to having an animal in the classroom.

"Kids with ASD can be just as unpredictable as a frightened dog. There are many factors that affect the success of a program like this"
"... Need to get parental approval and ensure there is not background of trauma with animals"

Of equal concern was the spread of disease and allergies of the children.

"Allergies are a major concern. I am very allergic to most animals and I would imagine many of our students could be."

"Due to the nature of high schools as students change classrooms every hour, concerns for the almost certain spread of bacteria affects allergies"

\section{DISCUSSION}

This study explored the attitudes and experiences of Australian school teachers' towards the use of animalassisted activities as a classroom based intervention for students with autism spectrum disorder. Despite limited knowledge, training, or experience with more formal therapies, teachers showed a positive attitude toward, and a high interest in pursuing the inclusion of animal-assisted interventions. Their interest was fuelled by a personal interest in animals; having previously witnessed the effective use of animals in the classroom; the belief that animals bring something unique to the classroom environment; and the belief that children with ASD often resonate with animals.

The teachers that had experience with animals in schools reported a range of benefits at the individual student and classroom level. The key benefits identified included improving social skills; facilitating student engagement by providing a means for the student to connect with the activity, teacher and peers; decreasing student stress and anxiety; and reducing classroom behavioural problems. These benefits mirror the positive teacher experiences reported elsewhere (Hergovich et. al. 2002; Kotrschal and Ortbauer 2003; Rud and Beck 2003; Prothmann et al. 2009), as well as studies identifying the benefits of children with ASD interacting with animals (O'Haire et al. 2013).

Of course, the use of animals or animal-assisted interventions in the classroom is not appropriate for all students (e.g. not all students like dogs, allergies), teachers (e.g. employment status), or situations (e.g. school, classroom setup, subject). Explanations as to 
why animal-assisted interventions were either not being adopted, or not currently considered included a lack of knowledge; lack of support and resources; extra workload; reactions of the student in relation to allergies and behaviour; and issues relating to animal welfare (both inside and outside of school hours). Although these reflect some of the barriers reported by Rud and Beck (2003), and more recently Ladarola et al. (2015), we found no indication that a lack of collegial or parental support was an issue for this sample of Australian teachers.

It is in the best interest of both schools and teachers to proactively source innovative interventions to support students with disabilities. Overall, this study revealed that Australian teachers are open to emerging or novel interventions to support students with ASD. In fact, teachers expressed a personal responsibility to seeking the most effective teaching strategies for their students. As few teachers had actually used any form of animalassisted interventions in their classroom, it is important that the barriers identified to doing so are addressed. Equally, resources that inform teachers, parents, and school administrators about animal-related programs must be made available.

The lack of evidence-base from which to form a decision to implement animal-related interventions for students with ASD was identified as an issue. The use of animals, although it may be incredibly beneficial for students, has yet to be supported by scientifically valid or reliable research in the classroom ( $\mathrm{O}^{\prime}$ Haire 2013; Kasari and Smith 2013). Thus, it is interesting that these teachers were willing to implement a time consuming and potentially financially costly intervention, despite a lack of evidence or training, and in a climate where it is often difficult to get schools to implement strategies and modifications that have been shown to genuinely make a difference (Ladarola et al. 2015). Indeed, it is important to keep an open mind in exploring different avenues, but there is an obligation to ensure that only interventions that have some empirical data and research base behind them are encouraged. Moving forward, it is imperative that the inclusion of companion animals and more formal based animal intervention programs or activities in classrooms be adequately evaluated, because implementing or promoting any strategies without evidence is problematic.

This scoping study represents a small sample of Australian teachers that relies on self-report. Additionally, it utilised a sample of convenience that likely attracted teachers with a pre-existing interest in animal-assisted interventions. A wider sample from a broad range of schools might reveal different attitudes, experiences, and barriers. There also may be some confusion among participants as to the nature of animal-related interventions (for example, around the differences between 'formal' animal-assisted therapies, and 'informal' animal-assisted activities). Although a definition of animal-assisted therapy was provided to the participants at the beginning of the survey, their understanding of these terms may have influenced their responses unintentionally. Despite these limitations, this study provides a useful starting point for further investigations into novel interventions that can support our increasing population of students with ASD. Equally important however, is to consider the attitudes and perspectives of the schools and school teachers because they will have the greatest influence on its adoption and its success.

\section{REFERENCES}

American Psychiatric Association. (2013). Diagnostic and statistical manual of mental disorders: DSM-5. Washington, D.C: American Psychiatric Association.

Anderson, K.L., and Olson, M.R. 2006. The value of a dog in a classroom of children with severe emotional disorders. Anthrozoös 19: 35-49. doi: 10.2752/089279306785593919.

Ascione, F.R., and Weber, C.V. 1996. Children's attitudes about the humane treatment of animals and empathy: One-year follow-up of a school-based intervention. Anthrozoös 9: 188-195. doi: 10.2752/089279396787001455

Australian Companion Animal Council. 2010. Contribution of the pet care industry to the Australian Economy. 7th edn. http://www.acac.org.au/pdf/ACAC \%20Report\%200810_sm.pdf. Accessed on November 16, 2015.

Beetz, A. 2013. Socio-emotional correlates of a school 
dog-teacher-team in the classroom. Frontiers in Psychology 4: 1-7. doi: 10.3389/fpsyg.2013.00886

Berry, A., Borgi, M., Francia, N., Alleva, E., and Cirulli, F. 2013. Use of assistance and therapy dogs for children with autism spectrum disorders: A critical review of the current evidence. The Journal of Alternative and Complimentary Medicine 19: 73-80. doi: 10.1089/acm.2011.0835

Braun, V., and Clarke, C. 2006. Using thematic analysis in psychology. Qualitative Research in Psychology 3: 77101. doi: 10.1191/1478088706qp063oa

Carlisle, G.K. 2015. The social skills and attachment to dogs of children with Autism Spectrum Disorder. Journal of Autism and Developmental Disorders 45: 11371145. doi: 10.1007/s10803-014-2267-7.

Chandler, C. (2001). Animal-assisted therapy in counseling and school settings (Report No. EDO-CG01-05). Greensboro, NC: ERIC Clearinghouse on Counseling and Student Services. (ERIC Document Reproduction Service No. ED459404).

Daly, B., and Suggs, S. 2010. Teachers' experiences with humane education and animals in the elementary classroom: implications for empathy development. Journal of Moral Education 39: 101-112. doi: $10.1080 / 03057240903528733$

Fine, A. ed. 2010. Handbook on animal-assisted therapy: Theoretical foundations and guidelines for practice (3rd ed). San Diego, CA: Elsevier.

Friesen, L., and Delisle. E. 2012. Animal-assisted literacy. Childhood Education 88: 102-107. doi: 10.1080/00094056.2012.662124

Grandgeorge, M., Tordjman, S., Lazartigues, A., Lemonnier, E., Deleau, M., Hausberger, M., and Young, L. 2012. Does pet arrival trigger prosocial behaviors in individuals with autism? PLOS ONE 7: 1-8. doi: 10.1371/journal.pone.0041739

Grandin, T., Fine, A. H., \& Bowers, C. M. 2010. The use of therapy animals with individuals with autism. In Handbook on animal-assisted therapy: Theoretical foundations and guidelines for practice (3rd ed), 247-264, ed. A.H. Fine San Diego, CA: Elsevier.

Green, J., Willis, K., Hughes, E., Small, R., Welch, N., Gibbs, L., and Daly, J. 2007. Generating best evidence from qualitative research: The role of data analysis. Australian and New Zealand Journal of Public Health 31: 545-550. doi: 10.1111/j.1753-6405.2007.00141.x

Hergovich, A., Monshi, B., Semmier, G and Ziegler, V. 2002. The effects and presence of a dog in the classroom. Anthrozoös 15: 37-50. doi: 10.2752/089279302786992775

Jalongo, M., Astorino, T., and Bomboy, N. 2004. Canine Visitors: The influence of therapy dogs on young children's learning and well-being in classrooms and hospitals. Early Childhood Education Journal 32: 9-16. doi: 10.1023/B:ECEJ.0000039638.60714.5f

Jalongo, M. 2005. What are all these dogs doing at school? Using therapy dogs to promote children's reading practice. Childhood Education 81: 152-158. doi: 10.1080/00094056.2005.10522259

Kaufmann, M. 1997. Creature Comforts: AnimalAssisted Activities in Education and Therapy. National Education Service 1: 27-31.

Kasari, C., and Smith, T. 2013. Interventions in schools for children with autism spectrum disorder: Methods and recommendations. Autism 17: 254-267. doi: $10.1177 / 1362361312470496$

Kotrschal, K. and Ortbauer, B. 2003. Behavioural effects of the presence of a dog in a classroom. Anthrozoös 16: 147-159. doi: $10.2752 / 089279303786992170$

Kršková, L., Talarovičová, A., and Olexová, L. 2010. Guinea pigs-The "Small Great" therapist for autistic children, or: do guinea pigs have positive effects on autistic child social behavior? Society and Animals 18: 139-151. doi: 10.1163/156853010X491999 
Ladarola S, Hetherington S, Clinton C, Dean M, Reisinger E, Huynh L, Locke J, Conn K, Heinert S, Kataoka S, Harwood R, Smith T, Mandell DS, Kasari C. 2015. Services for children with autism spectrum disorder in three, large urban school districts: Perspectives of parents and educators. Autism 19: 694703. doi: $10.1177 / 1362361314548078$

Lord, C., Wagner, A., Rogers, S., Szatmari, P., Aman, M., Charman, T., Dawson, G. et al. 2005. Challenges in evaluating psychosocial interventions for autistic spectrum disorders. Journal of Autism and Development Disorders 35: 695-708.

Nimer, J., and Lundahl, B. 2007. Animal-assisted therapy: A meta-analysis. Anthrozoös 20: 225-238. doi: 10.2752/089279307X224773

O'Haire, M. 2013. Animal-assisted intervention for autism spectrum disorder: A systematic literature review. Journal of Autism and Developmental Disorders 43: 1606-1622. doi: 10.1007/s10803-012-1707-5.

O’Haire, M.E., McKenzie, S.J., Beck, A.M., and Slaughter, V. 2013. Social skills increase in children with autism in the presence of animals compared to toys. PLOS ONE 8: e57010. doi: 10.1371/journal.pone.0057010

O'Haire, M.E., McKenzie, S.J., McCune, S., and Slaughter, V. 2014. Effects of classroom animal-assisted activities on social functioning in children with Autism Spectrum Disorder. Journal of Alternative and Complementary Medicine 20: 162-168. doi: 10.1089/acm.2013.0165

Prothmann, A., Ettrich, C., and Prothmann, S. 2009. Preference for, and responsiveness to, people, dogs and objects in children with autism. Anthrozoös 22: 161-171. doi: $10.2752 / 175303709 \times 434185$

Roth, L. 2013. Autism spectrum disorder, Briefing Paper No 5/2013. NSW Parliamentary Research Service. ISBN 978-0-7313-1901-5. Retrieved from http://www.parliament.nsw.gov.au/prod/parlment/publ ications.nsf/0/B2142391F94516FECA257B78001FB961/\$F ile/Autism\%20Spectrum\%20Disorder.briefing \%20paper.pdf. Accessed on November 16, 2015.

Rud Jr., A.G., and Beck, A.M. 2003. Companion animals in Indiana elementary schools. Anthrozoös 16: 241-251. doi: 10.2752/089279303786992134

Silva, K., Correia, R., Lima, M., Magalhães, A., and de Sousa, L. 2011. Can dogs prime autistic children for therapy? Evidence from a single case study. Journal of Alternative and Complementary Medicine 17: 655-659. doi: 10.1089/acm.2010.0436.

Smyth, C., and Slevin, E. 2010. Experiences of family life with an autism assistance dog. Learning Disability Practice 13: 12-17. doi:10.7748/1dp2010.05.13.4.12.c7758. 